\title{
Ecocritical Media Arts and the War on Terra
}

\author{
SEAN CUBITT \\ Professor of Screen Studies, Culture and Communication, University of Melbourne
}

\begin{abstract}
Ecocritique accepts, as it must, that humans and environments have been ripped apart historically, sociologically, and aesthetically. But it also recognizes that because we have become strangers, dialogue between humans and environments is possible as it could not be if we were all one universal flux. Because of our mutual alienation, there are endless opportunities for misunderstanding when we capture, store, and process what we confront as Nature. Contemporary economic and political conditions driving ever more terrifying inequalities of wealth and power create the crisis implicit in ecocritique. The critical functions of art, which in these circumstances implies technical and creative aesthetic and political practice, concern the construction of a "we" that embraces the human and non- human victims of ecocide. The master's tools might dismantle the master's house, but can they build a different dwelling? Where are the practices that can produce more-than- human social change?
\end{abstract}

We call media "media" because they mediate. That some media also communicate is a historical change that overcame media somewhere in the mists of time when humans emerged from their primal immersion in the world to become historical. History begins in this severance of humans from their ecology, which suddenly became environment, surroundings. History as the estrangement of humans and their world required communication to secure the difference and to secure communities from and in their differentiation from the world, a madly risky process. The further we have moved from any natural condition, the more we repress senses and body from the admissible zone of human culture, the more perilous our mediations become, and the more essential. Understanding how (some) media work tells us a great deal about the macro- and micro-histories of our species' exile, of the fraught tale of becoming human. All our relations with one another and the world are mediated, and media are evidence of separation as much as they attempt to bridge it. The relation between human, media, and world, the object of so much film and media theory, ${ }^{1}$ and its remaking in and through the necessity of media, is the royal road to an ecocritical aesthetic politics. Here I take the shift from film to video as an exemplary microhistory illuminating how we became so alienated, and how mediation itself can take us, not back to some primal union, but forward through our alienation and out to the other side.

"Cinema is truth twenty-four times a second." Jean-Luc Godard's aphorism in Le petit soldat (1960/1963) takes on a new life in the video era, not just because cinema, like video, is now almost exclusively twenty-five frames per second, but because the frames are now composed of 
rows of pixels, scanned from the top left to bottom right, building, and fading, in eternal incompletion. Film frames were complete unto themselves: the whole frame was projected for its brief duration on screen. With scanned images, the whole image is never there in its entirety. But the two systems have one thing in common: frames (and scanlines) must succeed one another, twenty-four or twenty-five times a second.

Godard prefaces the famous line about "truth twenty-four times a second" with the statement "Photography is truth." Clearly, he intended to say that the succession of true images constitutes another form of truth, a presence of things. Each time a full frame is projected, there is truth on the screen (and as his character says next, "and every cut is a lie"-every interruption of the continuum is untrue). In which case, when he moved towards video in his later career, a medium which, as we will see, cannot make a cut in the same definitive way as film, perhaps the distinction between truth and lie began to fade out of the moving image in favor of some other property - not necessarily less committed to reality, but less absolute. Most professions nowadays talk about probabilities, balances of evidence, demonstrable likelihoods, adequate explanations or theoretical credibility, and a raft of other such place holders - rarely about "truth" as such. Video occupies this subjunctive moment that even contemporary science embraces, aspiring to the highest degrees of what could, should, would, or might be the case. In common with other digital media, video tends to fork, in if-then logics, through NAND gates, never committing to a single, unique, irrefutable Now, as film used to. The theological absolute is now restricted to the circles of believers in God-given Truth. The rest of us rub along with the likely, the plausible, the notyet-disproved, where truth is not eternal but temporary-just like the video image.

It is also possible that Godard was thinking of something else that occurred twenty-four times a second in the cinema: the closing of the camera's or the projector's shutter to mask the move of the film strip from one frame to another. This eye-deceiving blanking of the image disguises the smear that would have appeared if the filmstrip moved with the shutter open, if the image actually moved, instead of simply being replaced by another behind the masking blankness of the closed shutter. Where is the truth in cinema? It is there in every one of those twenty-four times that the screen is blanked, the audience is cast into darkness, and nothing appears. Appearance, after all, for much of the history of Western and Eastern philosophy, has been the enemy of truth. Truth in cinema is the black strip between frames; it is darkness, the void, the non-communicating, the unapparent, the invisible. Truth is not-knowing. As Lacan used to say, "Le réel, c'est l'impossible," the real is the impossible that lies beyond image and symbol, language, and representation, all our techniques of meaning and organization, what is indeed defined by its exclusion as that which is impossible because, not being symbolic, it cannot be thought. ${ }^{2}$ Like the silence between words, the black screen that returns endlessly in cinema is its ultimate truth. ${ }^{3}$

Video uses a different technique. Each pass leaves just enough luminosity for the eye to retain while the oldest parts of the image fade-that black scanning band that is familiar from shots of TV screens refilmed without synchronizing the camera to the replay. When the frame refreshes, with interlaced scanning, you might see the same image again, but when it fades the image is changed - not the image you just saw but another one takes its place. True, the next image might be the same: which is what you see when you look at a still image on a phone, tablet, or computer, but it pulses with the effort of maintaining itself in visibility - in the realm of the possible. In film there was never a truly moving image; in video there is never a truly still one. The screen fades and refreshes, fades and refreshes, whatever content it displays, perpetually 
repeating itself, perpetually unstill. But it is like film, all the same, in the sense that for fleeting moments in some area of the screen there is nothing.

We aren't conscious of these nothings. We are unconscious. Not in the Freudian sense of a bubbling of embodiment just below the threshold of consciousness, but in the sense of concussion. Virilio describes it as the medical condition of picnolepsia, a momentary break in the stream of thought known also as a petit mal seizure: a gap, an absence from the world ${ }^{4}$ Film and video depend on our lapsing into unconsciousness twenty-four times a second, absenting ourselves from perception so that things can appear continuous. The moving image media may well be Godard's privileged vehicles of truth not because there is a privileged relationship between reflected light and the photographic filmstrip or optoelectronic chip, but because of the constitutive lacunae of light, movement, and consciousness that coincide every time we see motion on screen. We see motion because, twenty-five times a second, nothing moves. Let's take this literally. Nothing is present, and it moves.

I promised to talk about ecocritical media, so let us consider this proposition ecologically. There are two possibilities. Either there exists a force in nature which we can call Nothing or names like the Void, Vacuum, or Zero, or the Empty Set. Or there is no such thing in nature itself, but a force we call Nothing emerges in the relation between human beings and nature, or at least in some relations between nature and humans. Let's start with the second.

The relation that interests us is the one established through moving image media. It is a technological relation. It works by sampling light and sound from the world and re-presenting it as an audiovisual display suited for human senses, for example squeezing the further reaches of the electro-magnetic spectrum into the optical range, or, specifically, displaying the samples in sequence at a speed just above the limit where we would see the gaps between samples. Of all the multiple philosophies of technology that have emerged in the last two hundred years, for ecological criticism the most useful is Marx's description of it as “dead labor": technologies are skills developed by past workers, like weaving or welding, abstracted and congealed into machines. The skills (and today we should add the knowledges, languages, and symbols) agglutinated in machines are the skills of those who died before us, but, unlike indigenous peoples, we rarely know or respect the names of our ancestors. We only keep them locked in black boxes and demand that they serve the living, or, if not the living as such, then the needs of their designers, who in general are corporate research labs. If the technological relation is what produces the Nothing that is the truth of the moving image, then that nothing is very specifically the product not only of a historical epoch dominated by capital but, in its contemporary forms such as the MPEG codec, by profit.

So, the condition of unconsciousness specific to video belongs to corporate capital. But what is capital doing with consciousness? There persists in popular discourse the simplistic quasi-Marxist analysis that media took over religion's role as the opium of the masses. A more complex and satisfying hypothesis, developed initially by Walter Benjamin and widely debated in the 1970s, proposes that media are not purely ideological or even platforms for consumption but part of the production apparatus. ${ }^{5}$ Media exist to convert the attention of audiences into profit. ${ }^{6}$ In this sense, moving-image media are part of the extraction industry. Their role is to take a naturally occurring commons - human consciousness - and turn it into a raw material for processing and 
commodification. In our time, the raw material is attention, the valuable ore is called data, and its processed form is information. The picnoleptic effect is then a by-product of the extraction of consciousness for use in the production of profit. It requires our at first willing and now habitual suspension of consciousness. It requires us to think of ourselves not as parts of a human ecology of languages, knowledges, and skills - as a human commons - but instead as components of a system designed to attract consciousness and extract surplus value from it by selling it on in the information economy. Video is a device designed to turn human beings into externalities - the economic term for unpaid resources like oceans and mountains that can be mined (and dumped into) at no economic cost to the corporation mining them. In this way, we discover that our wage for supplying this valuable commodity is: Nothing. That momentary blindness that overcomes us between frames is not so much a medical condition as the moment when we are hoodwinked (eyes blink as a bag is pulled over the head).

The second possibility was that Nothing exists as a quality in nature, like gravity. Like gravity, nothing is difficult to see, smell, touch, or even weigh, but its effects are everywhere. We could work out some properties: if nothing exists, it must be symmetrical in all directions, because there is nothing in nothing to differentiate it from itself, so we know that nothing is nothing all the time and everywhere. And since, where there is stuff, there is no nothing, then nothing must fit in the gaps between stuff, surrounding it, creeping in when stuff vacates a part of space-time. Thus, nothing is what is left when you remove everything else.

This position is entirely hypothetical, but it chimes with the digital-capital-as-picnoleptic hypothesis: resource extraction transforms consciousness as social commons into consciousness as economic externality, and in that process leaves behind pockets of nothingness. This is one point of purchase for an ecocritical aesthetics of the media arts that reaches beyond moral outrage and sentimental or nostalgic defense strategies for lost wholeness. The classic examples of externalities are things like seas and rivers, forests and prairies, either enclosed and turned into private property, or held in common under law but made available for commercial exploitation. We call such resources environments because they environ, that is, because they are excluded from the core business of profit, and set outside it, beyond the account book, unaccounted for, of no account, nothing. Human consciousness becomes nothing when it becomes environmental. Twenty-four times a second, we blink into existence; twenty-four times a second, we blink out of it. Half the time we are in the world; half the time we are absent. The obverse is also the case: half the time, the world is absent. The only question is: which half?

What disappears into the blanks between images is not only consciousness but our connection with the world. In this, video imitates the environmental relationship at large. The difference between ecology and environment is that everything is interconnected in an ecology, but an environment is a product of exclusion, of disconnection. In this light we would have to say that video is an environmental medium, but not an ecological one: it is a medium of disconnection.

At the same time, we have to go back to defining technology. The design of technologies, their organization, depends on black-boxing the ancestors. But technologies are material things, made of glass, metals, and plastic, and they need energy to run on. So, while video technology may be designed to disconnect humans and environments, materially they are ecological, connected to the Earth through supply chains and factories, chemicals and carbon emissions. So, again, while on one hand video is made out of ancestors, on the other video is a machine for extracting 
consciousness, a process which, as it becomes more automated on social and streaming media, turns more consciousness into machinery. The implication is that the process is speeding up; our skills and knowledge are being harvested and technologized while we are still living, and we are becoming ancestors while we watch.

At the same time, media technologies are black boxes. We know little about how they work, and less about how they operate in vast networks handling (technically speaking) unimaginable quantities of uploads, far more than the entire population can pay attention to. Their audience is to a great degree exclusively machinic (for example the machines that scrutinize CCTV footage).

All this goes on with a design input from humans and careful extraction of profit, but unsurprisingly, for the vast majority of the human population and all of the non-human environment, technology appears as another environment. The technological environment is every bit as excluded as the natural one.

There is a contradiction between ecological connection and environmental disconnection that extends to technologies, including media technologies. ${ }^{7}$ It seems as if it might arise from the tension between actual ecological connection (as materials and energy) and designed environmental disconnection, where "design" is to be understood as a function of corporate control over planning and implementation. A related contradiction sees humans as at once those who exclude environments and as themselves in the process of being excluded, either as raw resources, or as ancestral technologies. Somewhere in this thicket, the Western intellectual tradition demands, there should lie the true center, the place where it all comes from, the power behind the throne. This paper has already insinuated that this center is capital; but in a historically specific form which we can call corporate cyborgs. We thought the cyborg would look like Arnold Schwarzenegger, human with chips implanted, but the obverse is the case. The actually existing cyborg is a huge network of computers and databases with human implants. You can tell corporations are cyborg because they lack the instinct for survival, helplessly driven by an indesigned hunger for profit at whatever cost, including exhausting the resources they depend on and poisoning the consumers they rely on, up to the point of planetary apocalypse.

An alternative possibility is that human beings could do the things that corporations do. The hypothesis of the corporate cyborg as éminence grise, the true center of power and corruption, the Father of Lies, may mask the terrible possibility that humans are capable of this genocidal, terracidal horror. It is also possible that the paranoid dream of the ultimate center is a myth - not just a fantasy to protect the ecological optimist from the awful truth of human evil, but a story of wide cultural circulation capable of carrying fears and desires in ways that make social as well as personal life tolerable. Journalists want you to believe they are close to The Center; politicians want you to believe they have the ear of the Fat Controller; the Stock Exchange wants you to believe that they have the perfect oracle to translate the Will of the Market. These mythopoeic tales: are they fabrications? What if there is no center? What if there is only Nothing, zilch, nada, zero?

The mathematical name for nothing, zero, has attracted its own mathematical conundrums. The mathematical philosopher Frege observed that in logic, the rule of self- identity says that anything that exists must be identical to itself: this apple is this apple; A equals A. So, he says, how do we define zero? If whatever exists obeys the law of self-identity, and by definition zero 
does not exist, then zero can be defined as the non-identical. ${ }^{8}$ Now we have a Nothing that can really kick ass.

Nothing redefined as Frege's zero is not just vacuum. It is the seething void of non-identity, where stuff happens (perhaps symmetrically, perhaps universally) but no things, no self-identities crop up. This kind of nothing looks a lot more like a force. It also looks a lot more like an activity to be excluded. Cyborg corporations want to exist; they perpetrate an economic system based on things, treat natural and technical environments and humans themselves as things, operate in consort with populist ideas of the nation state as a thing constituted by borders. The last thing they want is a nothing that seethes with non-identity. Cyborg politics, like military strategy, is founded on 4CI: Command, Control, Communication, Computers, and Intelligence. What is it trying to exclude? What is 4CI's name for the horror of unformed non-identity? The true name of Nothing, the truth that cinema realized twenty-four times a second, the blank consciousness that permeates our attempts to connect with the world, what else can we call it but Noise.

I realize I have now spent a lot of my time and your attention talking about Nothing. To bring this, finally, back to media, as promised, let's consider the single most influential statement on media from the last century, Claude Shannon's 1949 Mathematical Theory of Communication. ${ }^{9}$ There, you will remember, he reduced communication to the engineering problem of getting a message from a sender via a channel to a receiver, and the completion of the loop through a feedback mechanism equating to the response "received and understood." Or perhaps just "received," since Shannon was at pains to note that although "[f]requently the messages have meaning... These semantic aspects of communication are irrelevant to the engineering problem." What was significant was "reproducing at one point either exactly or approximately a message selected at another point." The enemy of this more-or-less accurate, statistically measurable model of communication was Noise. There are two possible sources of noise: outside and inside. External noise is, strictly defined, environmental: it comes from sunspots, electrical storms, the acoustics of a busy office. Internal noise is generated in the system itself, the crunching of parts, construction errors, transmission errors, problems with lens design... We might translate these into noise deriving from the natural and the technical environments respectively. Shannon's challenge was to provide a working telephone system in the era of mass post-war suburbanization in the USA. His mathematical model would underpin 4CI approaches, including the development of VHF and UHF broadcasting, global video standards, and the initial development of the internet under DARPA, the Defense Advanced Research Projects Agency and its subsequent commercial applications. The mathematical theory of communication is the dominant ideology of the twentyfirst century, in the sense that it is the ideology that the dominant forces in society deploy when they are dominating. Its goal is efficiency, defined variously as clarity, minimal waste of energy, and profitability, the three qualities tightly bound together and mutually defining.

What is not sought or desired is interference, natural, systemic, or deliberate. Noise is inefficient. Pure noise is statistically random. It is entropic, the opposite of orderly. Noise is waste-waste heat, waste electromagnetic radiation or waste sounds that escape being used for work and thus for profit. Noise is unproductive. It has no place in a system devoted to efficient delivery of clear reproductions from A to $\mathrm{B}$. Noise is non-identical, it adds Nothing, it is the second law of thermodynamics in action, a premonition of the heat-death of the universe. It has to be suppressed. It must be suppressed because it is the evidence of our expulsion from Eden. We wanted to be free of nature. Half the glitches in communication derive from the ecology of 
radiation we deny in our assertions of autonomy - most of all the solar radiation on which everything Earthly depends. The other half comes from the suppression of human nature that we attempt by black-boxing our ancestors and, in effect, our own bodies and senses. ${ }^{10}$ These closed systems are not closed, but neither are they coherent. Every technical system generates its own noise.

The same is true of the subject of all this. The flickering unconsciousness of the moving image spectator does have a Freudian dimension. Freud wrote of the return of the repressed: the persistence of noise in even the most regulated communication is a symptom of the return of the suppressed. And what has been suppressed? The two environments, nature and technology, and in a further residue, the uncontrolled activities of unregulated humans, the kind you try to block out when you make a call from a crowded street. (We could call that the urban environment, in recognition of the alienation of the city's fabric from its users.) Shannon's devotion to message meant excluding both meaning and environment, suggesting to the critical reader that there might be some connection between the two. There is every reason to believe that meaning is intrinsically social (after all, no one invents their own language from scratch), and from there it is a short step to arguing that language and all the other media we use to communicate are also intrinsically ecological, drawing their materials and their semantics from the mutual interrelations that constitute the world. This is what Shannon's communication excludes. This primary ecological interplay of everything with everything else we can refer to as "mediation," to make clear its materiality and its ecological intermixing, as opposed to the linear delivery of packets of information that comprises "communication."

Shannon was not wrong - truly powerful ideologies rarely lie or falsify. He described an existing state of affairs, at least from a specific perspective, but his evaluation was upside down. Communication separates senders from receivers and both from messages. Mediation does not need to connect: everything is already implicated in everything else. Mediation is ontology, as the philosophers say: it is real. Communication belongs to humans. It takes time. Communication is historical; indeed, there is a case to be made that communication is why we have history in the first place. Communication starts history by severing humans from their environments, including the technological channels that become technical environments: real mediations at war with the dream of perfect communication. From Communication's point of view, mediation is noise. History is the story of the war between communication and mediation, communication and noise.

Which is why, and how, the media arts operate in communications media, that oxymoronic, selfcontradictory phrase.

Take Rosa Menkman's lovely Collapse of PAL (2011). ${ }^{11}$ Menkman went at her video tape camera with a soldering iron to prepare it for a video essay drawing on Walter Benjamin's lines about the angel watching the catastrophe of progress to witness the end of analog video. ${ }^{12}$ She made the video signal revert to its electromagnetic flux while filming. ${ }^{13}$ The landscape she reveals is part natural, part electronic, a hybrid. There is also, not so often remarked, the prototypical glitch that video shares with the cine camera, because both are lens-based: the lens flare. There's an odd story about lens flares. When Thomas Knoll's brother John began work as a visual effects supervisor in Hollywood, he asked brother Thomas to create what would become Photoshop's first filter, a plug-in to produce virtual lens flare, so he could make computer generated images 
look as if they had been made with a real camera in real sunlight. (John later patented lens-flare software of his own.) Introducing a deliberate error, one that cinematographers go to extreme lengths to avoid, into CGI was a brilliant way to emulate the materiality of a physical lens in a real place where neither lens nor place existed. Menkman's flare is, however, a product of actual sun-strike, an actual lens, in some actual if uncanny place - uncanny because it is ambivalently natural and technical, doubly estranged. The reality of the landscape, its "truth" in Godard's language, is this ambivalence and exteriority.

This is somehow different from datamoshing, for example the kind that Takeshi Murata was using back in 2005 on Monster Movie ${ }^{14}$ where the compression is deliberately lossy, and the found footage from a camp B-movie collapses into blocks of pixels. Video signals are busy bits of technology. The dominant form is MPEG, a compression-decompression protocol or codec for short, another derivative of the Shannon model, also reliant on producing just enough fidelity at the far end to get a message through without wasting too much energy trying to make the resemblance perfect. MPEG works in near real time - a term heavy with the complex realities it hides - cutting the video stream into segments, typically shots or, if the shots are long, finding places in long takes where enough changes in the frame make a snip feasible. The first and last frames of the snippet are treated as keyframes, as in animation, and sent in relatively high resolution. In-between frames are treated with less respect, as in the animation studios' low-paid in-betweening work. Comparing first and last keyframes, the codec selects the areas of the image with the most changes (faces for example) and sends more information for those areas than it does for dark backgrounds or green playing fields. The frames are split into units of blocks, groups of blocks, and irregularly shaped slices, some sent in detail, some not. As an additional saving, rather than sending information for every pixel, some blocks - representing a ball on a football pitch for example - are not tracked frame by frame. Instead the codec supplies an algebraic expression of the curve through the frame that the "ball" passes through, using the technique called vector prediction. These operations lose lots of detail, and add some movements that may not have been there in front of the camera. They also send a stream of metadata telling the receiver how to reassemble the sequence of frames, especially useful if they are being streamed over the internet, which uses another cut-and-paste technology, packet-switching, to send video files. Messing about with the control metadata and other elements of the codec produces unpredictable effects.

The beauty of Murata's Monster Movie is that it brings the codec in as co-producer of the video. Instead of serving the just-good-enough principle of communication delivery, the technology gets to play. But what is still frightening about the result is that when the ancestors come out to play after centuries in black boxes, there is always the possibility that they have gone mad. As long as there is something human-like in the frame, the algorithm will seek it out, in the way Picasso would elaborate on a studio scene in the great inventions of cubism around 1906, where a kind of colonial-decolonial, desiring-hating argument between form and content, or between form, content, and meaning, goes on and goes off in the "philosophical brothel" of the Demoiselles d'Avignon. In the later passages of Monster Movie when the source footage is no longer decipherable, another kind of logic emerges, for which we have only the word "abstraction," but which seems to point, as abstraction so often has in art history, towards a consciousness beyond the human. 
Menkman's Collapse is closer to Jacques Perconte's Árvore da Vida, ${ }^{15}$ which also operates on the level of the codec, but now with a kind of evolutionary subtlety that datamoshing rarely strives for. Perconte disassembled more than a hundred thousand frames of video shot at a distance of two hundred meters from a tree standing at the edge of a Madeiran forest. The frames were stored as GIFs, before applying color reductions (well below the 256 usually allowed by the GIF format, passing as low as two or four colors) and MPEG-derived temporal compressions, before reassembling the near-monochrome plates in transparent layers up to twenty deep in After Effects to gain the maximum detail in the image, so that the titular tree of life and its backdrop shimmer with one life. (This is a much-shortened account of the process; and the video documentation available on streaming platforms falls far below the cinema-quality resolution of the original.)

In a lucid and poetic text, Bidhan Jacobs writes, "The motif of the tree of life, principle of fertility and fecundity, is injected into the digital film technologies whose normalized, impoverished signal contains in its data an infinite plastic potential," as if Perconte's patient labors on the files reveal an otherwise hidden digital capacity for evolution and growth. ${ }^{16}$ Here it is the human artisan who places himself in service to the generative potential locked up in the black box of the codecs.

A last example of Nothing at work and play: Bill Morrison's Decasia ${ }^{17}$ Morrison's essay works on archives of decaying nitrate film stock. It was produced on film. We are most likely watching a digital file, which has added its own artifacts to the imagery. I present it as an ode to the collaboration between human filmmakers and their technologies in the early twentieth century, the decay inherent in nitrate chemistry (it is a frightening close relative of nitroglycerine, prone to burn ferociously with the aid of oxygen incorporated into its molecular structure), and microbial life that has invaded the spools over the passing decades. Be reassured, all digital files decay as well: bitrot is as inherent in digital storage as chemistry is to film archives. ${ }^{18}$

In these four examples, in their different ways, noise, nothing, the non-identical, primal mediation reasserts itself under the second law of thermodynamics, but this time not as the ultimate destination of all systems, but as their underpinning. The truth that appears twenty-four times a second is the real that interrupts any communication, and which communication cannot avoid because it is grounded in it, ecologically and ontologically - really, in any language.

The media, audiovisual, time-based media especially, and the media arts as experimental and thus risky ventures at the limits of their capabilities, are privileged sites for this ecopolitical aesthetics. The modernist tradition of enquiries into medium specificity persists here when all four works query the materials they are made from, and never more so than in the testing of the pseudomaterialism that asserts that the real reality of digital media is code. Code falls apart, not only in its functioning, but as presence, as actuality, not only because it exists only when it is running, which would allow it to be Real in Lacan's sense of what persists, indeed insists, despite our inability to perceive or describe it. It falls apart because it is never there: it is an appearance, the reality of the appearance, of non-identity. We cannot see or know code because it is non-identical. This is where the glitch emerges from the dialectic of an incompletely excluded nature, an incoherently suppressed ancestral technology, and the necessarily communicative and therefore social work of humans. The media arts are exemplary because, with rare exceptions, they are irredeemably collective processes engaging vast networks of humans, technologies, and 
ecological resources to function at all. In the media arts, this absolutely necessary contingency, absolutely connected estrangement, generates the grounds for imagination, the one collaborative power we have to see past, present, and future other than as they present themselves: to ensure that appearance and disappearance, the logic of the moving image, informs the false presumption that there exists a reality that oppresses us. Only then can we stop oppressing reality (and incidentally that aspect of reality that we experience as our selves).

And finally, to tie all this ado about nothing to the theme of this special issue, the social must be redefined because humans have been ejected from it along with natural, technical, and urban environments and externalities. Activists need all the allies we can get: we must be in dialogue with our ecology not just to survive but to make a world worth living on. We must be in dialogue with our ancestors and our ancestral technologies. The triple dialogue of humans, ecologies and technologies must be communicative-all activism is media activism. Media activism, however, cannot survive on - and should reject-Shannon's model of efficient communication. Because media mediate they are noisy, and that noise is the privileged road for new mediations (signals, conflict resolutions) between the estranged orders of human, natural, and technological being. The task of politics - the discussion as to how we are to live well on this planet - will be mediated or it will not happen; and it must involve technical media or there will be no dialogue between human and natural. But we cannot leave the media technologies out of the discussion they enable, or keep our ancestors in their black boxes as dumb servants of a process that affects them as deeply as it does ourselves.

The Second Law proclaims the asymmetry of past and future. It cannot replace faith, and does not even offer hope, but asserts that a future persists, a future other than the present. And that is the truth-twenty-five frames and forty thousand scan-lines per second.

\section{ENDNOTES}

1. The role of the image as mediator between human and world is a central theme of Bazin, notably in André Bazin, "Ontology of the Photographic Image," in What is Cinema?, vol. 1, trans. Hugh Gray (Berkeley: University of California Press, 1967), 9-16; of Cavell in Stanley Cavell, The World Viewed, enlarged ed. (Cambridge MA: Harvard University Press, 1979 [1971]); and more recently of Rodowick in D.N. Rodowick, The Virtual Life of Film (Cambridge, MA: Harvard University Press, 2007).

2. Jacques Lacan, Le séminaire, Livre XI, Les quatre concepts fondamentaux de la psychanalyse (Paris, Le Seuil, 1973), 152. See also Castanet Didier, "Éditorial: 'L'impossible, c'est le réel, tout simplement': Jacques Lacan," L'en-je lacanien, 2 no 7 (2006): 5-7

3. Technical note: The darkness, the Nothing that appears, has two faces. As object of perception, it simply fails the fundamental test of existence. This zero condition is what appears: the nonidentity of non-entity (see below for an explanation of Frege's definition of zero). The other face is the entity it appears to: the subject. This subject, like the images in cinema, emerges out of the originary dark of non-identity. In this sense the subjectivity of the spectator in the dark is precisely unconscious. 
4. Paul Virilio, Lost Dimension, trans. Daniel Moshenberg (New York: Semiotext(e), 1991). See also Sean Cubitt "Picnolepsy," in The Virilio Dictionary, ed. John Armitage (Cambridge: Polity, 2013), 142-144.

5. Walter Benjamin, "The Work of Art in the Age of its Technological Reproducibility: Third Version," in Selected Writings, vol. 4, 1938-1940, eds. Howard Eiland and Michael W. Jennings (Cambridge MA: Bellknap Press/Harvard University Press, 2003), 251-283. For a sophisticated recent reworking of the hypothesis see Jonathan Beller, The Cinematic Mode of Production: Attention Economy and the Society of the Spectacle (Lebanon NH: Dartmouth College Press / University Press of New England, 2006).

6. Dallas Smythe, "Communications: Blindspot of Western Marxism," Canadian Journal of Political and Social Theory, 1 no 3 (1977): 1-27.

7. I have explored these themes in Finite Media: Environmental Implications of Digital Technologies (Duke University Press, 2017) and Anecdotal Evidence: Ecocritique from Hollywood to the Mass Image (New York: Oxford University Press, 2020). Further deliberations can be found in Stephen Rust, Salma Monani, and Sean Cubitt (eds.), The Ecocinema Reader: Theory and Practice (New York: Routledge/American Film Institute, 2012). Infrastructural ecocritique is furthered by studies collected in Nicole Starosielski and Janet Walker (eds.), Sustainable Media: Critical Approaches to Media and Environment (London: Routledge, 2016). For the expansion of ecocritical approaches to mainstream film see Jennifer Fay, Inhospitable World: Cinema in the Time of the Anthropocene (Oxford: Oxford University Press, 2018). For media arts, see Scott MacDonald, The Garden in the Machine: A Field Guide to Independent Films About Place (Berkeley: University of California Press, 2001).

8. Gottlob Frege, The Foundations of Arithmetic, trans. J.L. Austin, 2nd rev. ed. (New York: Harper, 1953).

9. Claude E. Shannon and Warren Weaver, The Mathematical Theory of Communication (Urbana: University of Illinois Press, 1949). Available from

http://people.math.harvard.edu/ ctm/home/text/others/shannon/entropy/entropy.pdf

10. Several recent writings address the link between bodily repression and glitch, notably Legacy Russell, Glitch Feminist Manifesto https://thesocietypages.org/cyborgology/2012/12/10/digitaldualism-and-the-glitch-feminism-manifesto/, Gregory Zinman, "Getting Messy: Chance and Glitch in Contemporary Video Art," in Gabrielle Jennings (ed), Abstract Video: The Moving Image in Contemporary Art, (Berkeley: University of California Press, 2015), and Caetlin Benson-Allott, "Going Gaga for Glitch: Digital Failure @ nd Feminist Spectacle in Twenty-First Century Music Video," in Carol Vernallis, Amy Herzog, and John Richardson (eds), The Oxford Handbook of Sound and Image in Digital Media (Oxford: Oxford University Press, 2013). If there is a weakness to these arguments, it is that in their urgent inquiry into embodied and gendered form, and their demand to queer the glitch, essential to the queering work of much contemporary ecocritical theory, they cannot address at the same time the cosmological externality of glitch to human concerns or the ancestral nature of the systems that revolt against their repression.

11. Rosa Menkman, Collapse of PAL (2011), https://vimeo.com/25410265

12. Walter Benjamin, "On the Concept of History," in Selected Writings, vol. 4, 1938-1940

(Cambridge MA: Bellknap Press/Harvard University Press, 2003), 389-400.

13. See here Rosa Menkman, Glitch Studies Manifesto (n.d.), http://amodern.net/wpcontent/uploads/2016/05/2010_Original_Rosa-Menkman-Glitch-Studies-Manifesto.pdf 
Rosa Menkman, A Vernacular of File Formats: A Guide to Databend Compression Design (2010), http://rosa-menkman.blogspot.co.uk/2010/08/vernacular-of-file-formats-2-workshop.html Rosa Menkman The Glitch Moment(um) (Amsterdam: Institute for Network Cultures, 2011).

14. Takeshi Murata, Monster Movie (2005), https://vimeo.com/147761897

15. Jacques Perconte, Árvore da Vida (2013), https://vimeo.com/60970370

16. Bidhan Jacobs, "Libération du Signal: les révolutions du Flou," L'Harmattan, 1 Sept. 2014.

17. Bill Morrison, Decasia (2002), https://vimeo.com/18511739

18. See inter alia Giovanna Fossati, From Grain to Pixel: The Archival Life of Film. (Amsterdam: Amsterdam University Press, 2009) and Matthew G. Kirschenbaum, Mechanisms: New Media and the Forensic Imagination. (Cambridge, MA: MIT Press, 2012).

\section{AUTHOR BIO}

Sean Cubitt is Professor of Screen Studies at the University of Melbourne. His publications include The Cinema Effect, EcoMedia, The Practice of Light, Finite Media, and Anecdotal Evidence. Series editor for Leonardo Books at MIT Press, his current research is on political aesthetics, ecocritique, and practices of truth. 